\title{
Particle Swarm Optimization and Shuffle Complex Evolution for Calibrating Xinanjiang Model Parameters
}

\author{
King Kuok KUOK, Po Chan CHIU \\ PhD, PEng. Faculty of Engineering, Computing and Science, Swinburne University of Technology Sarawak \\ Campus, 93350 Kuching, Sarawak, Malaysia. \\ kelvinkuok100@gmail.com \\ Department of Information Science, Faculty of Computer Science and Information Technology, Universiti \\ Malaysia Sarawak, 94300 Kota Samarahan, Sarawak, Malaysia. \\ chiupochan@yahoo.com
}

\begin{abstract}
Xinanjiang model, a conceptual hydrological model, is well known and widely used in China since 1970s. Xinanjiang model consists of large number of parameters that cannot be directly obtained from measurable quantities of catchment characteristics, but only through model calibration. Parameter optimization is a significant but time-consuming process that is inherent in conceptual hydrological models representing rainfall-runoff processes. This study presents newly developed Particle Swarm Optimization (PSO) and compared with famous Shuffle Complex Evolution (SCE) to auto-calibrate Xinanjiang model parameters. The selected study area is Bedup Basin, located at Samarahan Division, Sarawak, Malaysia. Input data used for model calibration are daily rainfall data Year 2001, and validated with data Year 1990, 1992, 2000, 2002 and 2003. Simulation results are measured with Coefficient of Correlation (R) and Nash-Sutcliffe coefficient (E2). Results show that the performance of PSO is comparable with the famous SCE algorithm. For model calibration, the best $R$ andE2 obtained are 0.775 and 0.715 respectively, compared to $R=0.664$ and $E 2=0.677$ for SCE. For model validation, the average $\mathrm{R}=0.859$ and average $E 2=0.892$ are obtained for $\mathrm{PSO}$, compared to average $\mathrm{R}=0.572$ and average E2 $=0.631$ obtained for SCE.
\end{abstract}

\section{Indexing terms/Keywords}

Conceptual rainfall-runoff model; Particle Swarm Optimization; Shuffle Complex Evolution; Xinanjiang model

\section{Academic Discipline And Sub-Disciplines}

Civil Engineering, Hydrology and Water Resources

\section{Council for Innovative Research}

Peer Review Research Publishing System

Journal: INTERNATIONAL JOURNAL OF COMPUTERS \& TECHNOLOGY

Vol 10, No 10

editor@cirworld.com

www.cirworld.com, member.cirworld.com 


\section{INTRODUCTION}

Xinanjiang model, a semi-distributed conceptual rainfall-runoff model was firstly developed in 1973 and published in English in 1980 (Zhao et al., 1980). Since its initial development in the 1970s, Xinanjiang model has been successfully and widely used in humid, semi-humid, even in dry area of China and elsewhere in the world for flood forecasting (Zhao, 1992; Zhao \& Liu, 1995). According to Ren et al., (2006), Xinanjiang model has the following advantages: (a) The runoff depth are computed over partitioned sub-catchments: (b) evapotranspiration estimation by a three-layer method; (c) runoff components are separated into surface, subsurface, and groundwater flows, according to flow velocity; and (d) relations between partial model parameters on different time scales, can be conveniently transferred across temporal scales. One of the examples is deriving the outflow coefficients of the free-water storage to groundwater and subsurface flow in an hourly model, from a daily model based on the fact that daily hydrological data are more available than hourly data in the real world.

Xinanjiang model consists of large number of parameters that cannot be directly obtained from measurable quantities of catchment characteristics, but only through model calibration. According to Cheng et al, (2006) and Liu et al. (2009), calibration of the parameters is the main challenge in the development of hydrological models. In early days, the model calibration was performed manually, which is tedious and time consuming due to the subjectivities involved. Therefore, there is a need to employ automatic calibration techniques, which enables the hydrologist to rely less on subjective judgement for calibrating Xianjiang model.

In this study two Global Optimization methods named as Particle Swarm Optimization (PSO) and Shuffle Complex Evolution (SCE) were identified to calibrate Xinanjiang model parameters automatically. PSO was selected as Kuok (2010) found that Particle Swarm Method (PSO) is more reliable and promising to provide the best fit between the observed and simulated runoff for Hydrologic Tank model Calibration. Meanwhile, SCE method was selected as it was claimed that the most effective and efficient GOM for calibrating Hydrological Tank model parameters (Cooper et al., 1997; Chen et al., 2005).

\section{PARTICLE SWARM OPTIMIZATION}

PSO algorithm, a simple group-based stochastic optimization technique, was developed by Kennedy and Eberhart (1995). It is initialized with a group of random particles that were assigned with random positions and velocities. These particles learn over time in response to their own experience and the experience of the other particles in their group (Ferguson, 2004). Each particle keeps track of its best fitness position in hyperspace that has achieved so far (Eberhart and Shi, 2001) and accelerate towards its own personal best for every iteration. Then, the fitness value for each particle's is evaluated by calculating a new velocity term for each particle based on the distance from its personal best, and also its distance from the global best position.

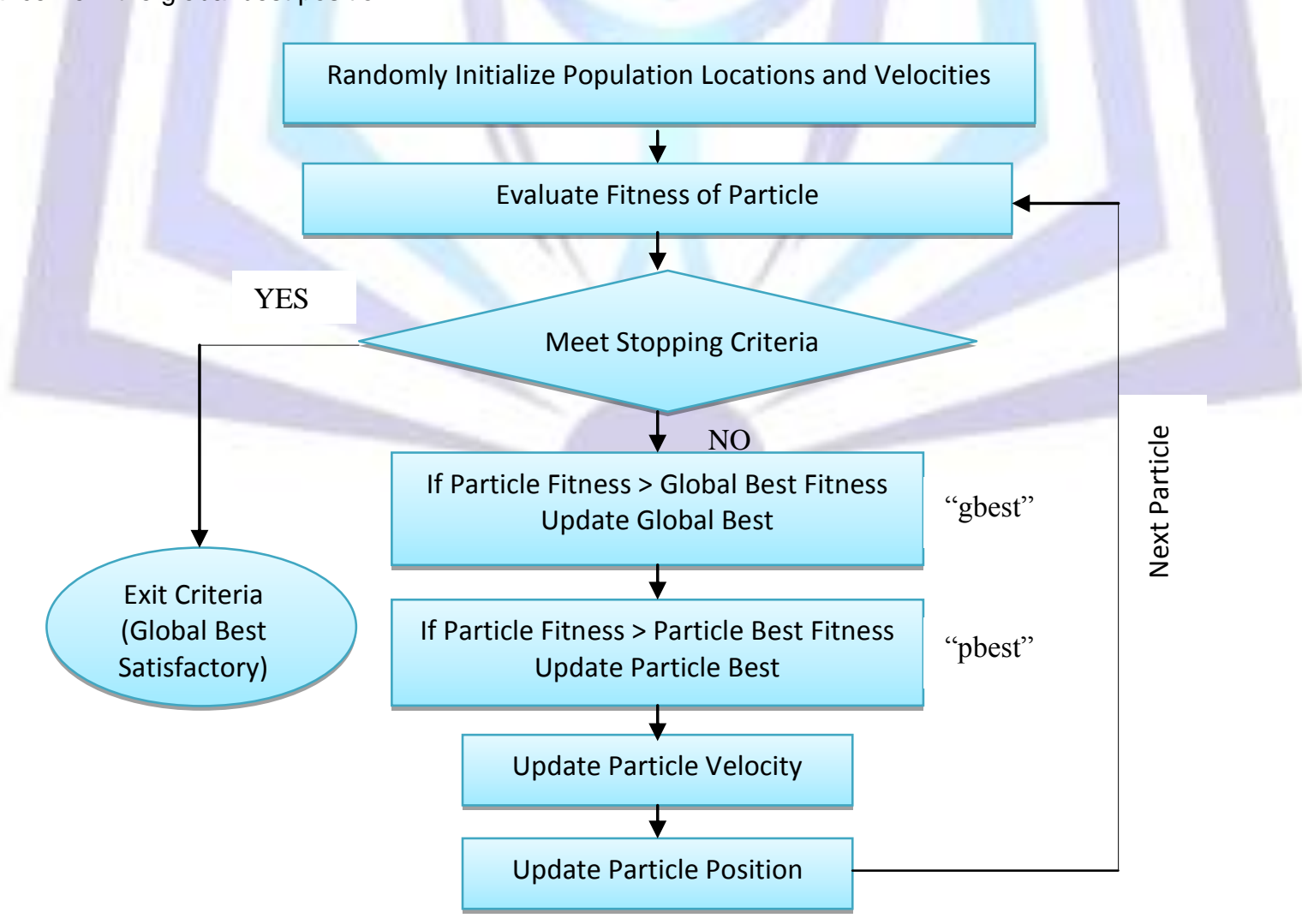

Fig. 1: Basic PSO Procedure. 
Once the particle achieved the best value, the particle stores the location of that value as "pbest" (particle best). The location of the best fitness value achieved by any particle during any iteration is stored as "gbest" (global best). The basic PSO procedure was shown in Fig. 1.

The particle velocity is calculated using Equation 1 .

$$
V_{i}=\omega V_{i-1}+c_{1}{ }^{*} \text { rand }()^{*}(\text { pbest-presLocation })+c_{2}{ }^{*} \text { rand }()^{*}(\text { gbest-presLocation) }
$$

The particle position is updated according to Equation 2.

$$
\text { presLocation }=\text { prevLocation }+V_{i}
$$

Where $V_{i}$ is current velocity, $\omega$ is inertia weight, $V_{i-1}$ is previous velocity, presLocation is present location of the particle, prevLocation is previous location of the particle and rand() is a random number between $(0,1) . c_{1}$ and $c_{2}$ are acceleration constant for gbest and pbest respectively.

\section{SHUFFLE COMPLEX EVOLUTION}

SCE algorithm was developed by Duan et al. (1994), using the best features of multiple complex shuffling and competitive evolution based on the simplex search method. SCE is the integration of four basic concepts: a) combination of random and deterministic approaches, b) concept of clustering, c) concept of a systematic evolution of a complex of points spanning the space, d) concept of competitive evolution. The 6 main steps involved in SCE algorithm are:

1. Generate the sampled points from the feasible space using upper and lower bounds of the parameters.

2. Sort and rank the sampled points in ascending order based on the criterion function values.

3. Partition the sampled points into complexes with predefined size of the complex population.

4. Evolve each complex independently with predefined number of times through reflection, contraction and mutation evolution steps.

5. Combine the evolved complexes from the previous step into a single sample population. Steps 3 to 5 are repeated until conditions as defined in step 6 are met.

6. Stopped the iteration if the number of evolutionary steps has exceeded a predefined value or the criterion value has not improved by a predefined percentage in a predefined number of steps.

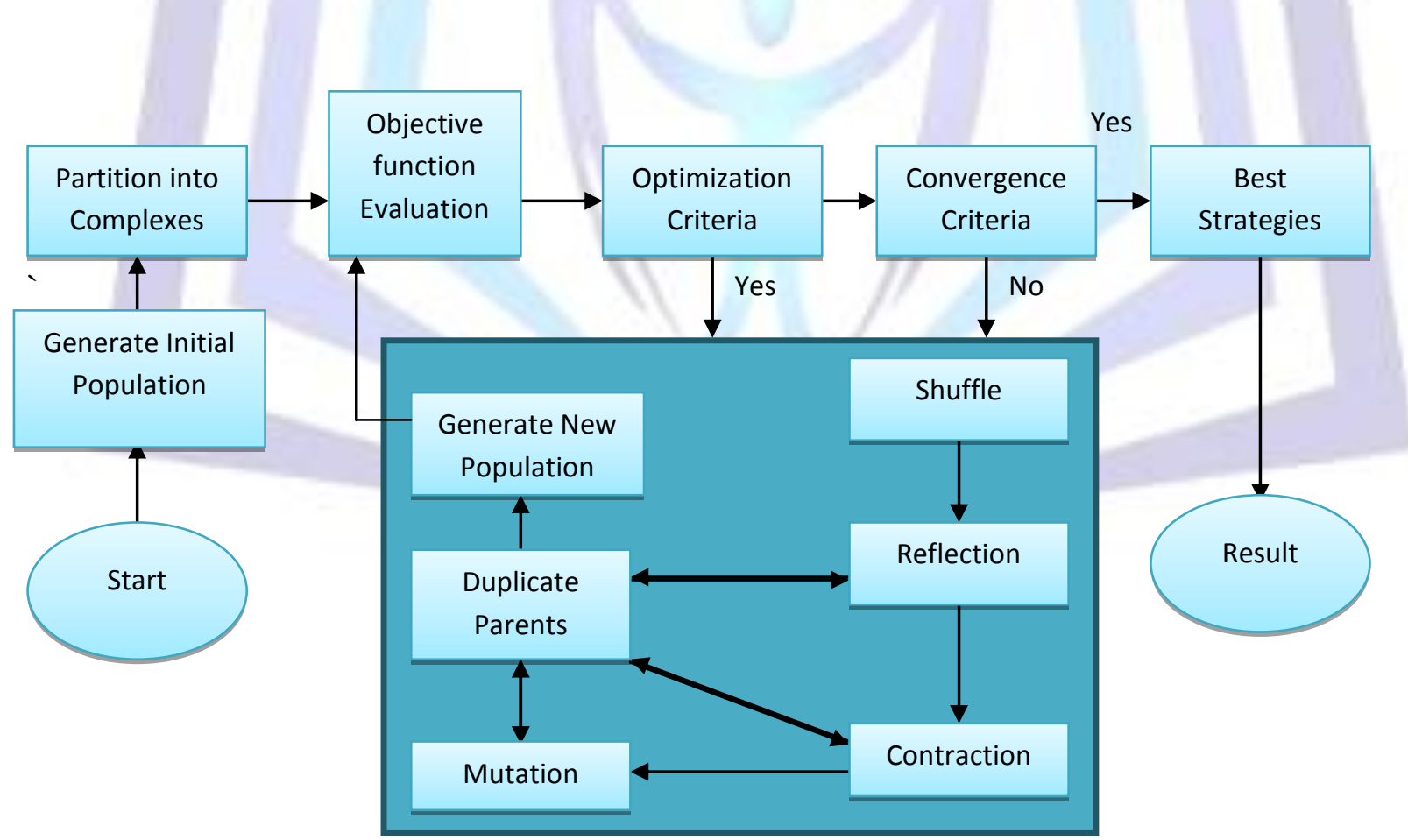

Fig. 2: SCE algorithm 
Once reached step 4 in SCE algorithm, Competitive Complex Evolution (CCE) will get into the procedure. CCE will reproduce new born and keep parents with stronger features, where each of the complexes will be developed separately before returning to the main stream of the procedure. All points in CCE have the chance to behave as parents in the way of reproduction. The duty of sub complexes is similar to parents except more than one parent can be utilized. Utilizing random method for the sub complexes enable users to conduct the search with complete converge of parameters domain. Schematic Diagram of SCE algorithm is presented in Fig. 2. Further details of SCE and CCE algorithm can refer to Duan et al. (1994).

\section{XINANJIANG MODEL ALGORITHMS}

The basic concept of runoff formation in Xinanjiang model is due to repletion of storage. Before the soil moisture content of the aeration zone reaching field capacity, runoff is not produced. Runoff is only generated at a point when the infiltration reached the soil moisture capacity (Zhao, 1983, 1992). Thereafter, the runoff is equal to excess rainfall without further loss. These processes are illustrated using tension water storage capacity curve, also named as parabolic curve of FC as presented in Equation 3 (Zhao et al., 1980).

$$
\frac{f}{F}=1-\left(1-\frac{W M s}{W M M}\right)^{b}
$$

Where WM'is the FC at a point that varies from zero to the maximum of the whole watershed WMM. LargerWM' means a larger soil moisture storage capacity in a local area and more difficult runoff generation. Parameter b represents the spatial heterogeneity of $F C$, as $b=0$ for uniform distribution and large $b$ for significant spatial variation, and it is usually determined by model calibration.

According to Ren et al., (2006), three kinds of spatially heterogeneous distributions are taken into consideration in the Xinanjiang model and there are:

(a) Uneven distribution of tension water storage capacity throughout the subcatchment is expressed by a parabolic curve for partial-area runoff generation;

(b) Non-uniform distribution of free water storage capacity over partial area where runoff has been produced, is expressed also in terms of a parabolic curve for separation of runoff into surface flow, interflow and groundwater flow;

c) The amount of free water storage is represented by the structure of linear reservoir for the sake of different velocities of different runoff components.

Fig.3 presents $\frac{f}{F}$ versus $W M^{\prime}$ curve. The watershed average $\operatorname{FC}(W M)$, is the integral of $\left(1-\frac{f}{F}\right)$ between $W M^{\prime}=0$ and $W M^{\prime}=$ WMM, represented by Equation 4.

$$
W M=\frac{W M M}{(1+b)}
$$

Meanwhile, the watershed-average soil moisture storage at time $t\left(W_{t}\right)$, is the integral of $\left(1-\frac{f}{F}\right)$, between zero and $W M_{t}^{8}$, which is a critical FC at time t as presented in Equation 5 and Fig. 3:

$$
W_{t}=\int_{0}^{W M_{t}^{*}}\left(1-\frac{f}{F}\right) d\left(W M^{\prime}\right)=W M\left[1-\left(1-\frac{W M_{t}^{*}}{W M M}\right)^{1+b}\right]
$$

The critical FC $\left(W M_{t}^{*}\right)$ corresponding to watershedaveragesoil moisture storage $W_{t}$ is presented in Equation 6 .

$$
W M_{t}^{*}=W M M\left[1-\left(1-\frac{w_{t}}{W M}\right)^{\frac{1}{1+b}}\right]
$$

When rainfall $(\mathrm{Pt})$ exceeds evapotranspiration $(\mathrm{Et})$, Pt is infiltrated into soil reservoir. Runoff (Rt) will only be produced when the soil reservoir is saturated (soil moisture reaches FC). As shown in Fig. 1, if the net rainfall amount (rainfall deduct actual evapotranspiration) in a time interval $[t-1, t]$ is $\mathrm{P}$-Et and initial watershed-average soil moisture(tension water) is $\mathrm{Wt}$, then runoff yield in the time interval, Rt can be calculated as follows.

$$
\begin{aligned}
& \text { If } P_{t}-E_{t}-W M_{t}^{*}<W M M \\
& R_{t}=P_{t}-E_{t}-\Delta W_{t} \\
& =P_{t}-E_{t}-\int_{W M_{t}^{*}}^{P_{t}-E_{t}+W M_{t}^{*}}\left(1-\frac{f}{F}\right) d\left(W M^{\prime}\right)
\end{aligned}
$$




$$
\begin{aligned}
& =P_{t}-E_{t}-W M+W_{t}+W M\left[1-\left(P_{t}-E_{t}-W M_{t}^{8}\right) / W M M\right]^{1+b} \\
& \text { If } P_{t}-E_{t}-W M_{t}^{8} \geq W M M \\
& R_{t}=P_{t}-E_{t}-W M+W_{t}
\end{aligned}
$$

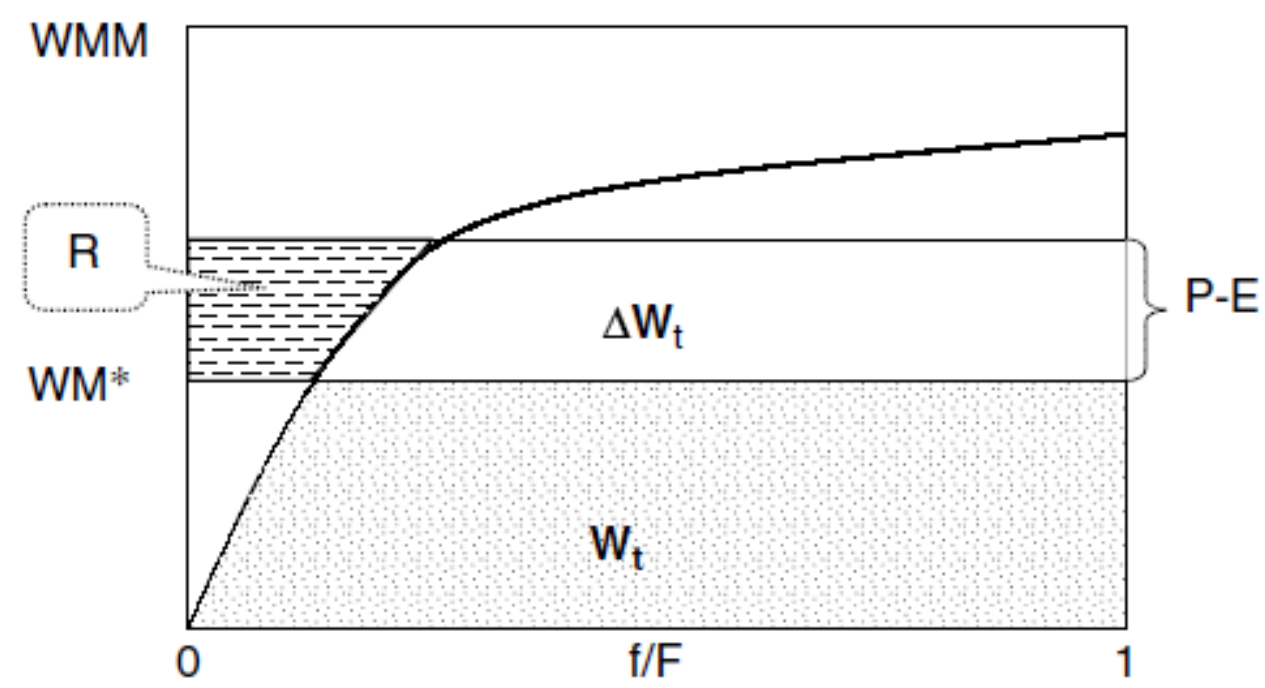

Fig. 3: FC curve of soil moisture and rainfall-runoff relationship.

Note: WMM is maximum FC in a watershed; $f / F$ is a fraction of the watershed area in excess of $F C$ $W M_{t}^{*}$ is $\mathrm{FC}$ at a point in the watershed; Rtis runoff yield at time $\mathrm{t}$; $\Delta \mathrm{Wt}$ is soil moisture storage deficit at time $\mathrm{t}$ and is equal to $\mathrm{WM}-\mathrm{Wt}$;

$\mathrm{Wt}$ is watershed-average soil moisture storage at time $\mathrm{t}$

The original Xinanjiang model is divided into two components named as runoff generating component and runoff routing component. Basin is divided into series of sub-areas, and runoff is calculated from water balance component. The runoff from each sub-area is routed to the main basin outlet using by Muskingum method. In this study, runoff generating and runoff routing components are combined together (refer to Fig. 4). 12 parameters to be calibrated are S, Dt, K, C, B, $\mathrm{Im}, \mathrm{Sm}, \mathrm{Ex}, \mathrm{Ki}, \mathrm{Kg}, \mathrm{Ci}$ and $\mathrm{Cg}$. The details of model parameters are presented in Table 1. During the calibration, the parameter must satisfy the constraints of the Muskingum method for each channel of subbasin.

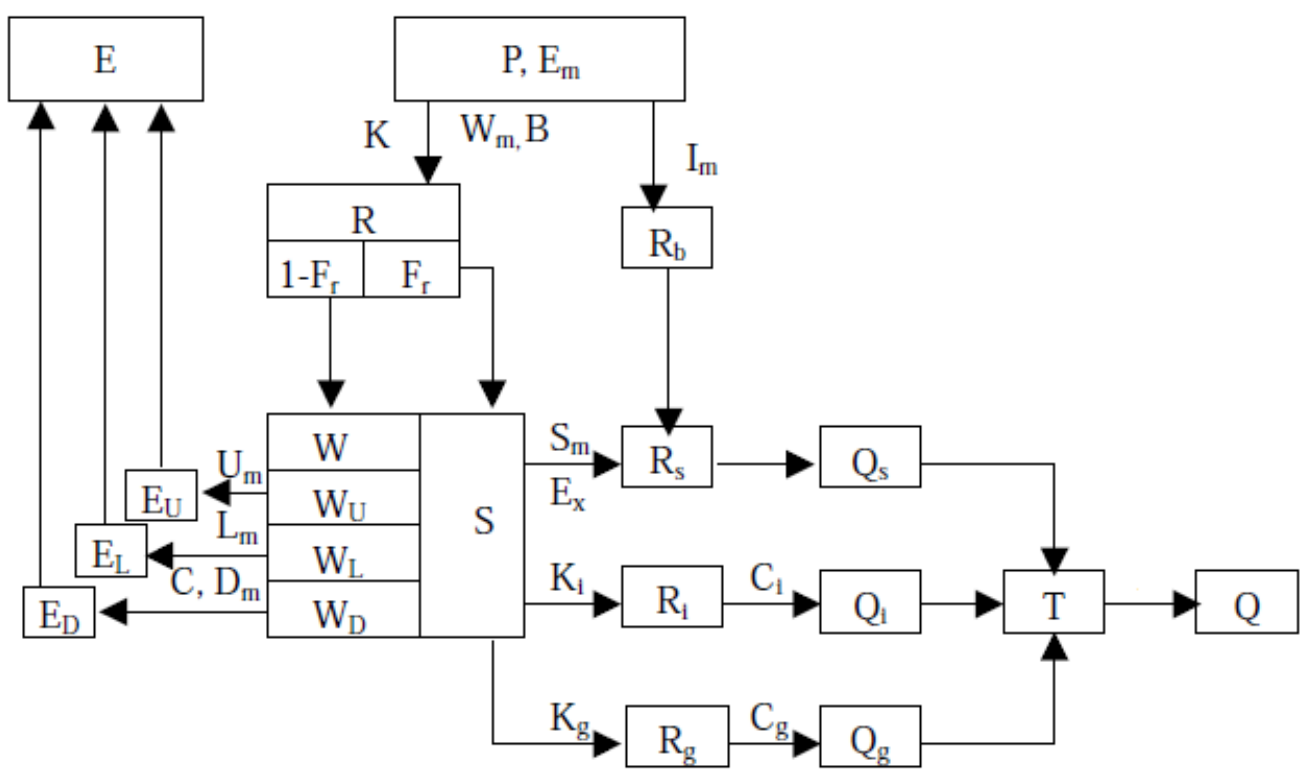

Fig.4: Flowchart of Xinanjiang Model 
Table 1: Parameters for Xinanjiang Model

\begin{tabular}{cl}
\hline Notation & Depth of free surface water flow \\
\hline St & Time interval \\
K & $\begin{array}{l}\text { Ratio of potential evapotranspiration to pan evaporation } \\
\text { Coefficient of the deep layer, that depends on the proportion of the basin area covered by } \\
\text { vegetation } \\
\text { with deep roots }\end{array}$ \\
& $\begin{array}{l}\text { Exponential parameter with a single parabolic curve, which represents the non-uniformity } \\
\text { of the spatial } \\
\text { distribution of the soil moisture storage capacity over the catchment }\end{array}$ \\
& $\begin{array}{l}\text { Percentage of impervious and saturated areas in the catchment } \\
\text { Im }\end{array}$ \\
Sm & $\begin{array}{l}\text { preal mean free water capacity of the surface soil layer, which represents the maximum } \\
\text { of free water storage } \\
\text { Exponent of the free water capacity curve influencing the development of the saturated } \\
\text { area }\end{array}$ \\
Ki & Outflow coefficients of the free water storage to interflow relationships \\
Kg & Outflow coefficients of the free water storage to groundwater relationships \\
Recession constants of the lower interflow storage \\
Cg
\end{tabular}

\section{STUDY AREA}

The selected study area is Bedup basin, with the approximate size of $47.5 \mathrm{~km}^{2}$, located $80 \mathrm{~km}$ from Kuching City, Sarawak, Malaysia. The catchment area is mainly covered with shrubs, low plant and forest, where there is no significant land use change over the past 30 years. Referring to topographic map produced by JUPEM (1975), the elevation of Bedup basin are varies from $8 \mathrm{~m}$ to $686 \mathrm{~m}$ above mean sea level. The length of Bedup river is approximately $10 \mathrm{~km}$. In general, Bedup basin is covered with clayey soils. Thus, most of the precipitation fails to infiltrate, runs over the soil surface and produce surface runoff. Part of Bedup basin is covered with coarse loamy soil, thus produced moderately low runoff potential.

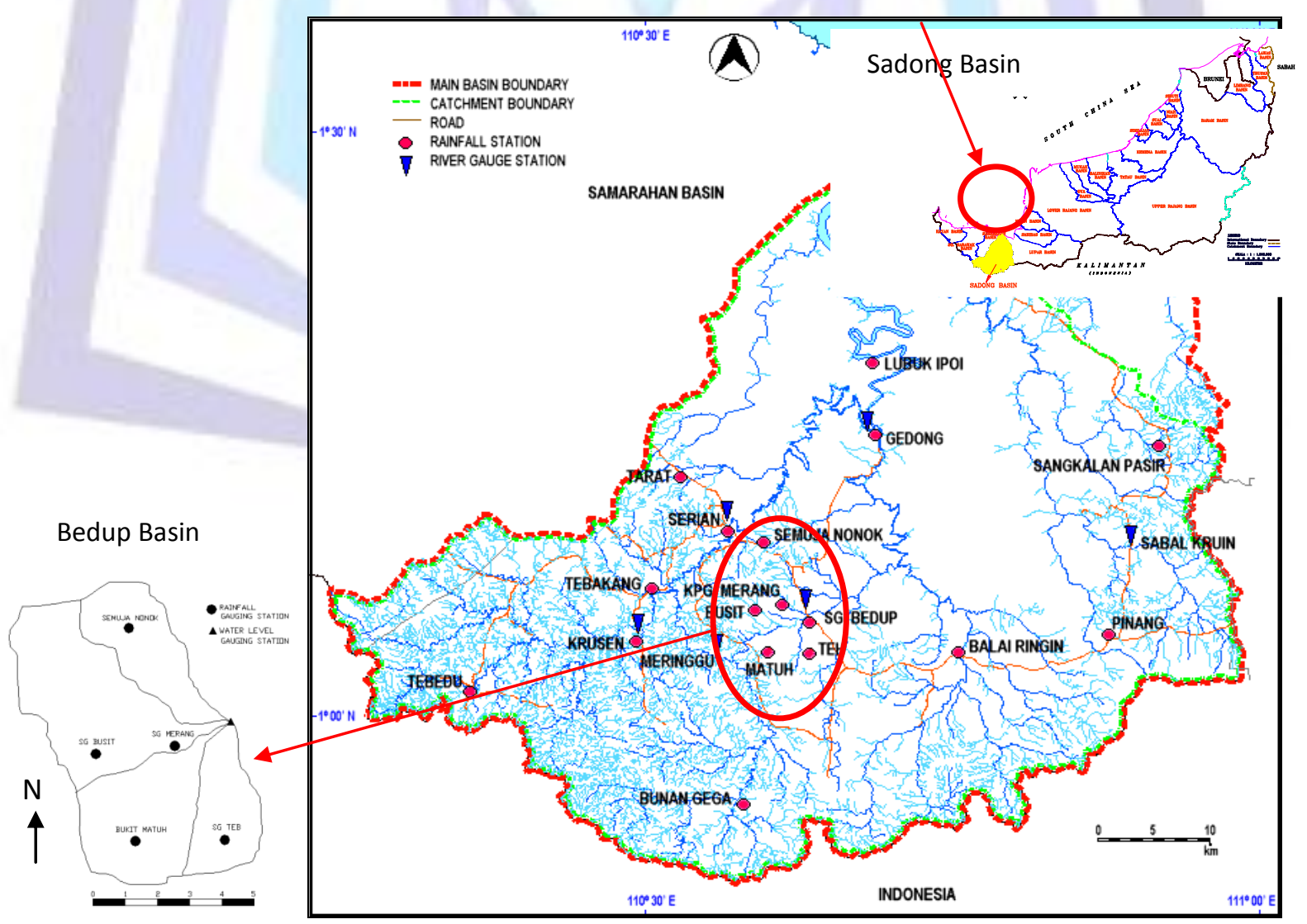

Fig 5: Locality map of Bedup basin, Sub-basin of Sadong basin, Sarawak 
Fig.5 presents the locality plan of Bedup basin. Sadong basin is located at southern region of Sarawak. Whilst Bedup basin is located at the upper catchment of Sadong basin and it is a non-tidal influence basin. Department of Irrigation and Drainage (DID) Sarawak has installed five rainfall stations include Bukit Matuh (BM), SemujaNonok (SN), Sungai Busit (SB), Sungai Merang (SM) and Sungai Teb (ST), and one river stage gauging station at the outlet of Sungai Bedup. The rating curve equation for Bedup basin is represented by Equation 7 (DID, 2007).

$$
Q=9.19(H)^{1.9}
$$

Where $Q$ is the discharge $\left(\mathrm{m}^{3} / \mathrm{s}\right)$ and $H$ is the stage discharge $(\mathrm{m})$. These observed runoff data were used to compare the model runoff.

Daily areal rainfall data that obtained through Thiessen Polygon Analysis are fed into Xinanjiang model for model calibration and validation. Area weighted precipitation for BM, SN, SB, SM, ST are found to be $0.17,0.16,0.17,0.18$ and 0.32 respectively. Thereafter, the calibrated Xinanjiang model will carry out computation to simulate the daily discharge at Bedup outlet.

\section{MODEL CALIBRATION AND VALIDATION}

The model parameterization and model calibration is an iterative process. If the defined parameter selected produce poor calibration results, the model parameterization should be reconsidered by defining a simpler conceptual model that includes fewer calibration parameters. In contrast, if the model is not able to describe the response of the system sufficiently, key model parameters should be reconsidered and include other process descriptions in the calibration. Lower and upper limits on each parameter are usually used to define the parameter space. These limits are chosen according to physical and mathematical constraints, and information about physical characteristics of the system and from modeling experiences. The basic calibration procedure for Xinanjiang model using PSO and SCE algorithms is presented in Fig. 6.

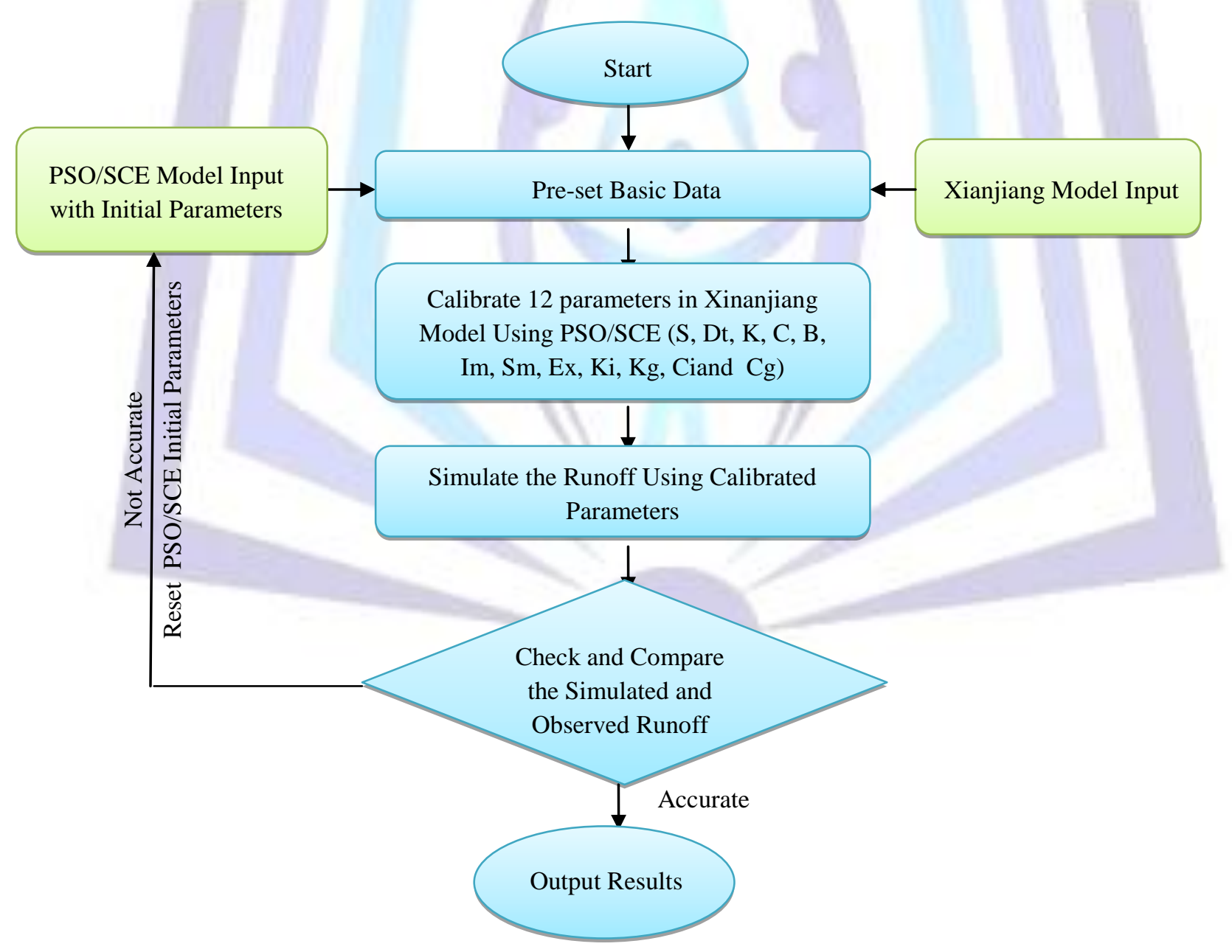

Fig. 6: Calibration procedure

The Xinanjiang model was calibrated with daily rainfall-runoff data year 2001. Since the model is firstly introduced in Malaysia, the best parameters values are not known. Therefore, all the 12 parameters include S, Dt, K, C, B, Im, Sm, Ex, $\mathrm{Ki}, \mathrm{Kg}, \mathrm{Ci}$ and $\mathrm{Cg}$, were calibrated automatically using PSO and SCE algorithms. 
At the early stage of the calibration, the parameters of PSO and SCE that will affect the calibration results are pre-set. Various sets of daily rainfall-runoff data were calibrated to find the best model configuration. The objective function used is Root Mean Square Error (RMSE).

As the calibration process is going on, the initial parameters that set previously are changed to make the simulated runoff matching the observed one. The parameters investigated for PSO algorithm include:
a) Different acceleration constant for gbest $\left(c_{1}\right)$ ranging from 1.0 to 2.0
b) Different acceleration constant for pbest $\left(c_{2}\right)$ ranging from 1.0 to 2.0
c) Max iteration of $100,125,150,175$ and 200
d) $100,125,150,175,200,225,250,275$ and 300 number of particles

Meanwhile, SCE algorithm is investigated with:

a) number of evolution steps for each complex before shuffling (nspl) ranging from 50 to 150

b) maximum number of function evaluations allowed during optimization (maxn) from 10000 to 200000

c) maximum number of evolution loops before convergency (kstop) from 50 to 500

The input data series to the Xinanjiang model are daily average areal rainfall calculated using Thiesen Polygon method. Daily data from $1^{\text {st }}$ January 2001 to $31^{\text {st }}$ December 2001 are used for model calibration. The model wastested with rainfallrunoff data year 1990, 1992, 2000, 2002 and 2003 for model validation. The details of data used for model validation are presented in Table 2.

Table 2: Daily Validation Data

\begin{tabular}{ll}
\hline & Validation Daily Data Set \\
\hline $\mathbf{1}$ & $1^{\text {st }}$ January 1990 to $31^{\text {st }}$ December 1990 \\
$\mathbf{2}$ & $1^{\text {st }}$ January 1992 to $31^{\text {st }}$ December 1992 \\
$\mathbf{3}$ & $1^{\text {st }}$ January 2000 to $31^{\text {st }}$ December 2000 \\
$\mathbf{4}$ & $1^{\text {st }}$ January 2002 to $31^{\text {st }}$ December 2002 \\
$\mathbf{5}$ & $1^{\text {st }}$ January 2003 to $31^{\text {st }}$ December 2003 \\
\hline
\end{tabular}

The accuracy of the simulation results are measured by Coefficient of Correlation $(R)$ and Nash-sutcliffe coefficient $\left(E^{2}\right)$. $R$ and $E^{2}$ are measuring the overall differences between observed and simulated flow values. The closer $R$ and $E^{2}$ to 1 , the better the predictions are. The formulas of $R$ and $E^{2}$ are presented in Equations 8 and 9 respectively.

$$
\begin{aligned}
& R=\frac{\sum(o b s-\overline{o b s})(\text { pred }-\overline{\text { pred }})}{\sqrt{\sum(o b s-\overline{o b s})^{2} \sum(\text { pred }-\overline{\text { pred }})^{2}}} \\
& E^{2}=1-\frac{\sum\left(o b s-\overline{\left.p_{r e d}\right)^{2}}\right.}{\sum(o b s-\overline{o b s})^{2}}
\end{aligned}
$$

Where $o b s=$ observed value, pred $=$ predicted value, $\overline{o b s}=$ mean observed values and $\overline{p r e d}=$ mean predicted values.

\section{RESULTS AND DISCUSSION}

\section{PSO Algorithm Results}

PSO algorithm achieved the optimal configuration at the RMSE of 2.3003. The optimal configuration for PSO algorithm was found to be 200 number of particles, max iteration of 150 and $c_{1}=1.8$ and $c_{2}=1.8$. The best $R$ and $E^{2}$ obtained for calibration set are found to be 0.775 and 0.715 respectively as presented in Fig. 7 . The 12 parameters of Xinanjiang model optimized by PSO algorithm can be found in Table 3.

The results show that runoff generated by Xinanjiang model optimized by PSO algorithm is controlled and dominant to 8 parameters include S, B, Im, Sm, Ex, Ki, Kg and Ci. In contrast, Dt, K, C and Cg are less sensitive to storm hydrograph generation.

Fig.8 shows the validation results when the optimal configuration of Xinanjiang model optimized by PSO algorithm. As $\mathrm{R}$ is referred, the results obtained for Year 2000, 2003, 2002, 1992 and 1990 are found to be $0.674,0.649,0.616,0.616$, 0.553 and 0.622 respectively. As E2 is used as level mark, the E2obtained are ranging from 0.550 to 0.623 . The average $\mathrm{R}$ and $\mathrm{E} 2$ are yielding to 0.622 and 0.579 respectively. 
Table 3: Optimized parameters for PSO model

\begin{tabular}{|cc|}
\hline Parameters & Values \\
\hline S & 5.1424 \\
\hline Dt & 0.00001 \\
\hline K & 0.00001 \\
\hline C & 0.00001 \\
\hline B & 0.0772 \\
\hline Im & 0.1542 \\
\hline Sm & 30.2411 \\
\hline Ex & 27.8412 \\
\hline Ki & 0.0521 \\
\hline Kg & 6.3272 \\
\hline Ci & 7.4719 \\
\hline Cg & 0.00001 \\
\hline
\end{tabular}

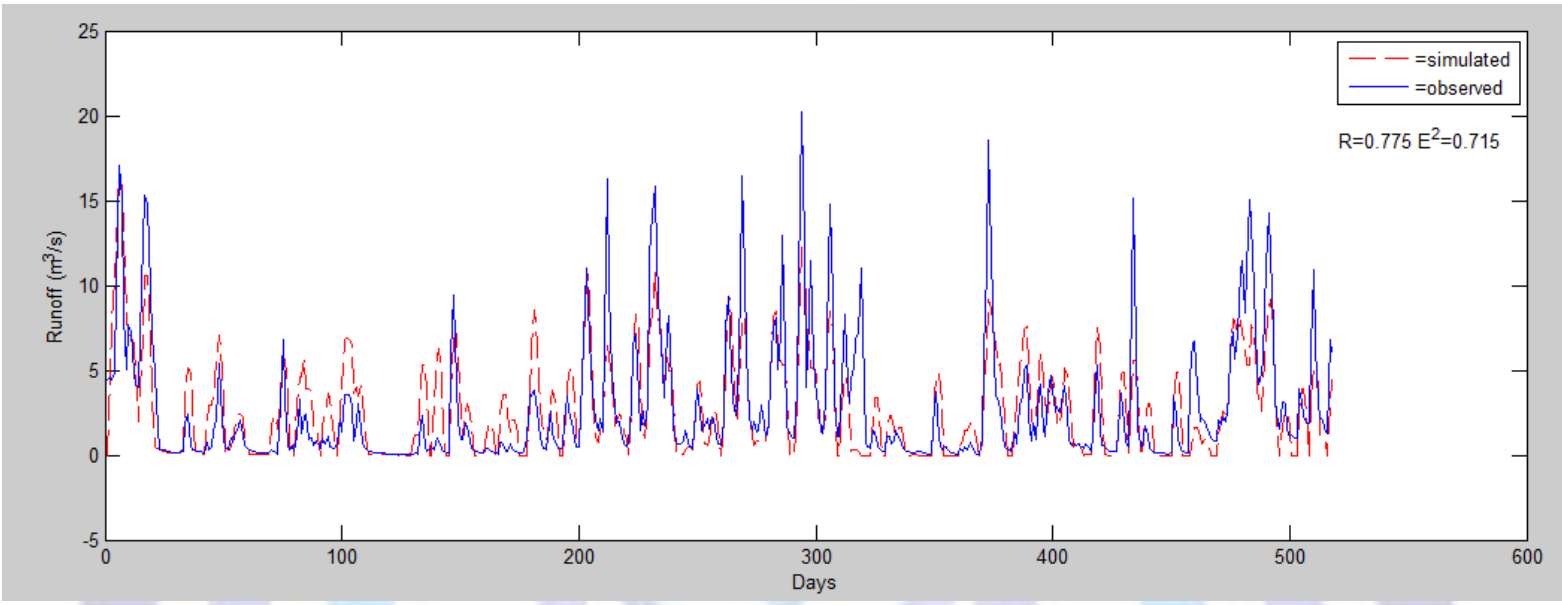

Fig. 7: Comparison between observed and simulated runoff generated by Xinanjiang model optimized with PSO algorithm.

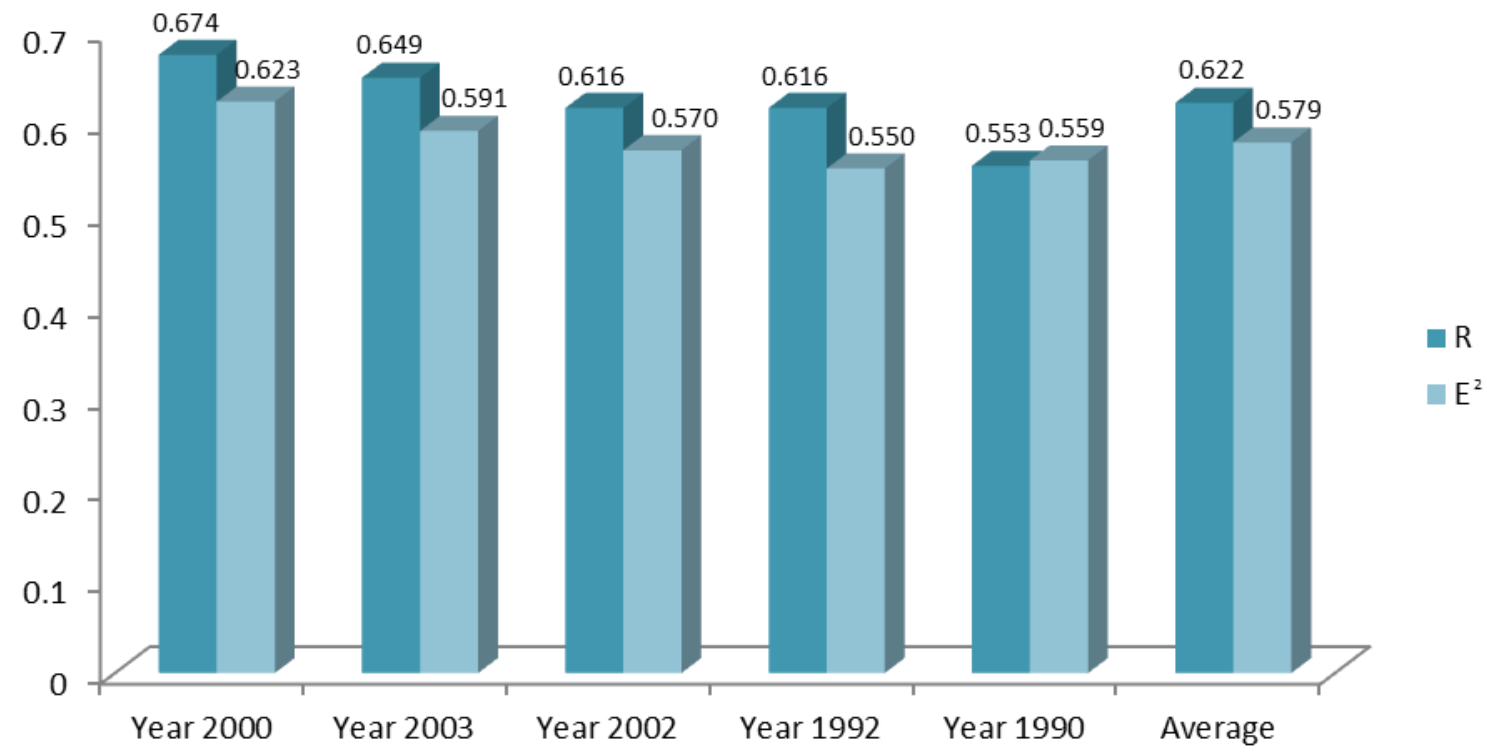

Figure 8: PSO model validation results

\section{SCE Algorithm Results}

The optimal configuration of SCE algorithm is obtained at maxn=10000, kstop=100 and nsp1 of 101 with RMSE of 3.1536 . The best $R$ and $E^{2}$ are found to be 0.664 and 0.677 respectively for calibration set (as presented in Fig. 9). Optimal 12 parameters of Xinanjiang model obtained by SCE algorithm can be found in Table 4. The results indicate that Xinanjiang 
model optimized by SCE algorithm is dominant to 11 parameters except Dt. This implicate that all the 11 parameters include $\mathrm{S}, \mathrm{K}, \mathrm{C}, \mathrm{B}, \mathrm{Im}, \mathrm{Sm}, \mathrm{Ex}, \mathrm{Ki}, \mathrm{Kg}, \mathrm{Ci}$ and $\mathrm{Cg} \mathrm{B}$ and $\mathrm{Cg}$ are sensitive and have significant impact to runoff generation.

As the optimal configuration of Xinanjiang model is validated with 5 different years rainfall-runoff data, $R$ values obtained for Year 2000, 2003, 2002, 1992 and 1990 are 0.542, 0.602, 0.583, 0.590 and 0.543 respectively, and 0.717, 0.566, $0,576,0.646$ and 0.650 for $E^{2}$. Average $R$ and $E^{2}$ for validated rainfall-runoff data are 0.572 and 0.631 respectively (refer to Fig. 10).

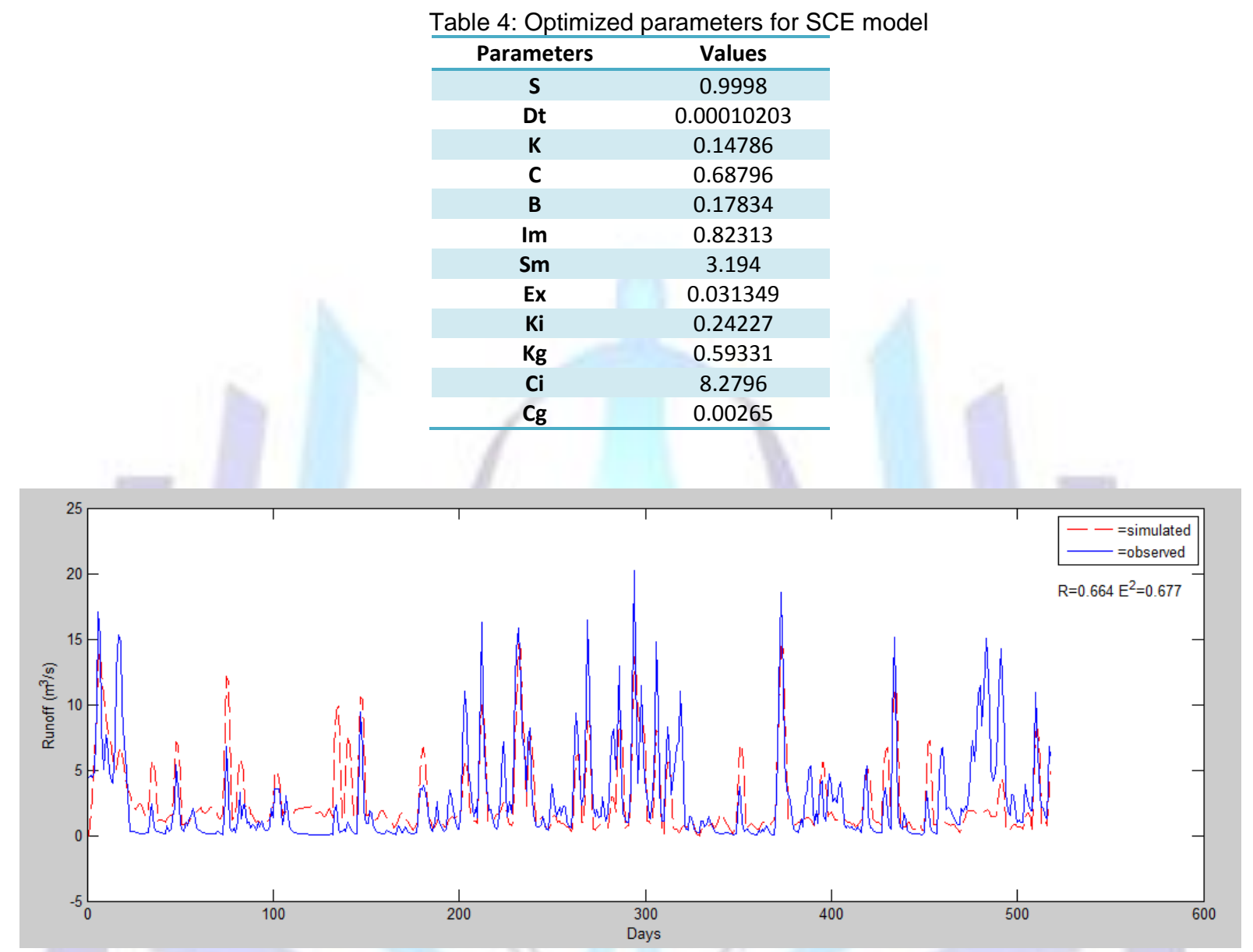

Fig. 9: Comparison between observed and simulated hourly runoff generated by Xinanjiang model optimized with SCE algorithm.

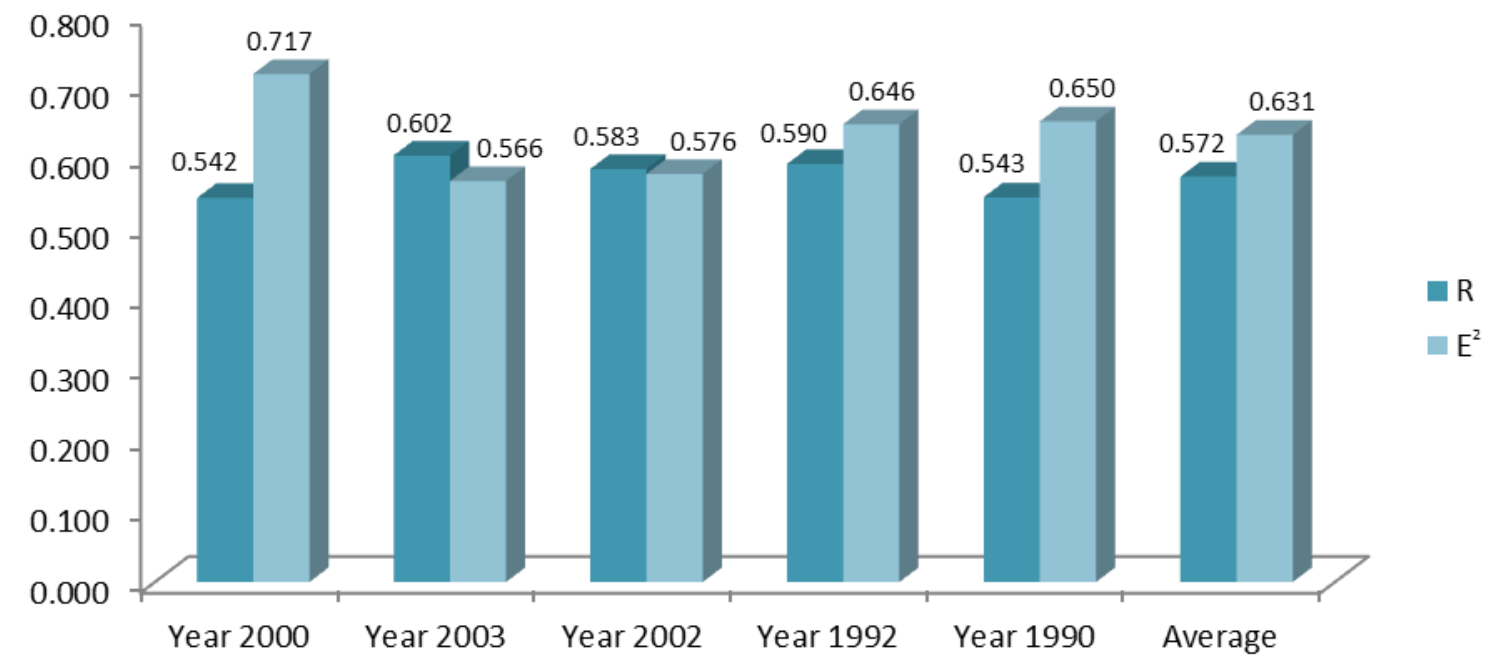

Figure 10: SCE model validation results 


\section{Conclusion}

In this study, two modelling studies were carried out to evaluate the effectiveness of PSO and SCE algorithms for optimizing Xinanjiang model. Results show that both algorithms have successfully calibrated Xinanjiang model for simulating daily runoff at Bedup Basin, Malaysia. For model calibration, PSO had achieved $R=0.775$ and $E^{2}=0.715$ with optimal model configuration of $c_{1}=1.8, c_{2}=1.8,200$ number of particles and 150 max iteration. Meanwhile, optimal configuration of SCE algorithm is also obtained at $\operatorname{maxn}=10000$, kstop $=100$ and nsp 1 of 101 that yield $R$ and $E^{2}$ to 0.664 and 0.677 respectively.

The results show that the newly developed PSO algorithm is comparable with the famous SCE algorithm. PSO had proven it is more robust by yielding average $R$ and $E^{2}$ to 0.622 and 0.579 respectively for 5 different sets of rainfall-runoff data, compared to average $R=0.572$ and $E^{2}=0.631$ for SCE model. These indicate that PSO optimization search method is a simple algorithm, but proved to be robust, efficient and effective in searching optimal Xinanjiang model parameters.

\section{ACKNOWLEDGMENTS}

The authors would like to express their sincere thanks to Professor Chun-Tian Cheng from Institute of Hydropower \&H ydroinformatics, Department of Hydraulic Engineering, Dalian University of Technolgy and Assocciate Professor Jintao Liu, Laboratory of Hydrology, Water Resources and Hydraulic Engineering, Hohai University, Nanjing for providing the source code of Xinanjiang model.

\section{REFERENCES}

[1] Chen, R.S.; Pi, L.C.; Hsieh, C.C., (2005). A study on automatic calibration of parameters in tank model. Journal of the American Water Resources Association (JAWRA).

[2] Cheng, C.T.; Zhao, M.Y.; Chau, K.W.; Wu, X.Y., (2006).Using genetic algorithm and TOPSIS for Xinanjiang model calibration with a single procedure. Journal of Hydrology 316 (2006) 129-140.

[3] Cooper, V.A.; Nguyen, V.T.V; Nicell, J.A., (1997). Evaluation of Global Optimization Methods for Conceptual RainfallRunoff Model Calibration. Water Sci. Technol. 36(5):53-60.

[4] DID, (2007). Hydrological Year Book Year 2007. Department of Drainage and Irrigation Sarawak, Malaysia.

[5] Duan, Q.; Sorooshian, S.; Gupta, V., (1994). Optimal use of the SCEUA global optimization method for calibrating watershed models. Journal of Hydrology 158, 265-284.

[6] Eberhart, R.; Shi, Y., (2001). Particle swarm optimization developments, Application and Resources. IEEE, 1, 81-86

[7] Ferguson, D., (2004). Particle swarm. University of Victoria, Canada.

[8] Kennedy, J.; Eberhart, R. C., (1995). Particle swarm optimization.Proceedings of the IEEE international joint conference on neural networks, IEEE Press.1942-1948.

[9] Kuok K. K., (2010). Parameter Optimization Methods for Calibrating Tank Model and Neural Network Model for Rainfall-runoff Modeling. Ph.D. Thesis. University Technology Malaysia.

[10] Liu, J.T.; Chen, X.; Zhang, J.B.; Flury, M., (2009). Coupling the Xinanjiang model to a kinematic flow model based on digital drainage networks for flood forecasting. Hydrological Processes.23, 1337-1348.

[11] JUPEM, (1975). Jabatan Ukur dan Pemetaan Malaysia. Scale 1:50,000.

[12] Ren, L.L.; Huang, Q.; Yuan, F.; Wang, J.X.; Xu, J., Yu, Z.B.; Liu, X.R., (2005). Evaluation of the Xinanjiang model structure by observed discharge and gauged soil moisture data in the HUBEX/GAME Project. Proceedings of symposium S7 held during the Seventh IAHS Scientific Assembly at Foz do Iguaçu, Brazil, April 2005

[13] Zhao, R.J.; Zhuang, Y.L.; Fang, L.R.; Liu, X.R.; Zhang, Q.S., (1980). The Xinanjiang model.In Hydrological Forecasting, IAHS Publication No.129. IAHS Press: Wallingford; 351-356.

[14] Zhao, R.J., (1983). Watershed Hydrological Model-Xinanjiang Model and Shanbei Model. Water \& Power Press: Beijing, (in Chinese).

[15] Zhao, R.J., (1992). The Xinanjiang model applied in China. Journal of Hydrology 135: 371-381.

[16] Zhao, R.J.; Liu, X.R., (1995). The Xinanjiang model. In: Computer Models of Watershed Hydrology (ed. by V. P. Singh), 215-232. Water Resources Publications, Colorado, USA. 


\section{Author' biography with Photo}

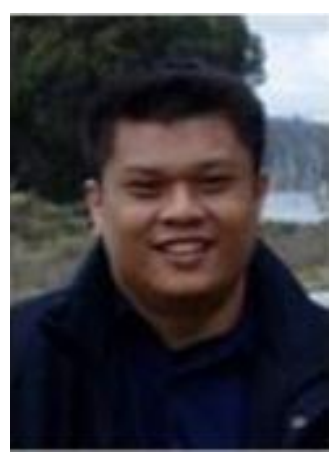

Ir. Dr. Kuok King Kuok holds PhD in Hydrology and Water Resources and Bachelor of Civil Engineering with honours, both from University Technology Malaysia, Master of Engineering major in Hydrology from University Malaysia Sarawak. He is also a Professional Engineer registered with Board of Engineers Malaysia, EMF International Professional Engineer (MY), Asean Chartered Professional Engineer. He is also a corporate member of Institution of Engineers Malaysia, ASEAN Engineer and APEC Engineer. He has authored and co-authored more than 30 national and international conference and journal papers. Currently he is lecturing at Swinburne University of Technology Sarawak Campus and also practicing as design engineer.

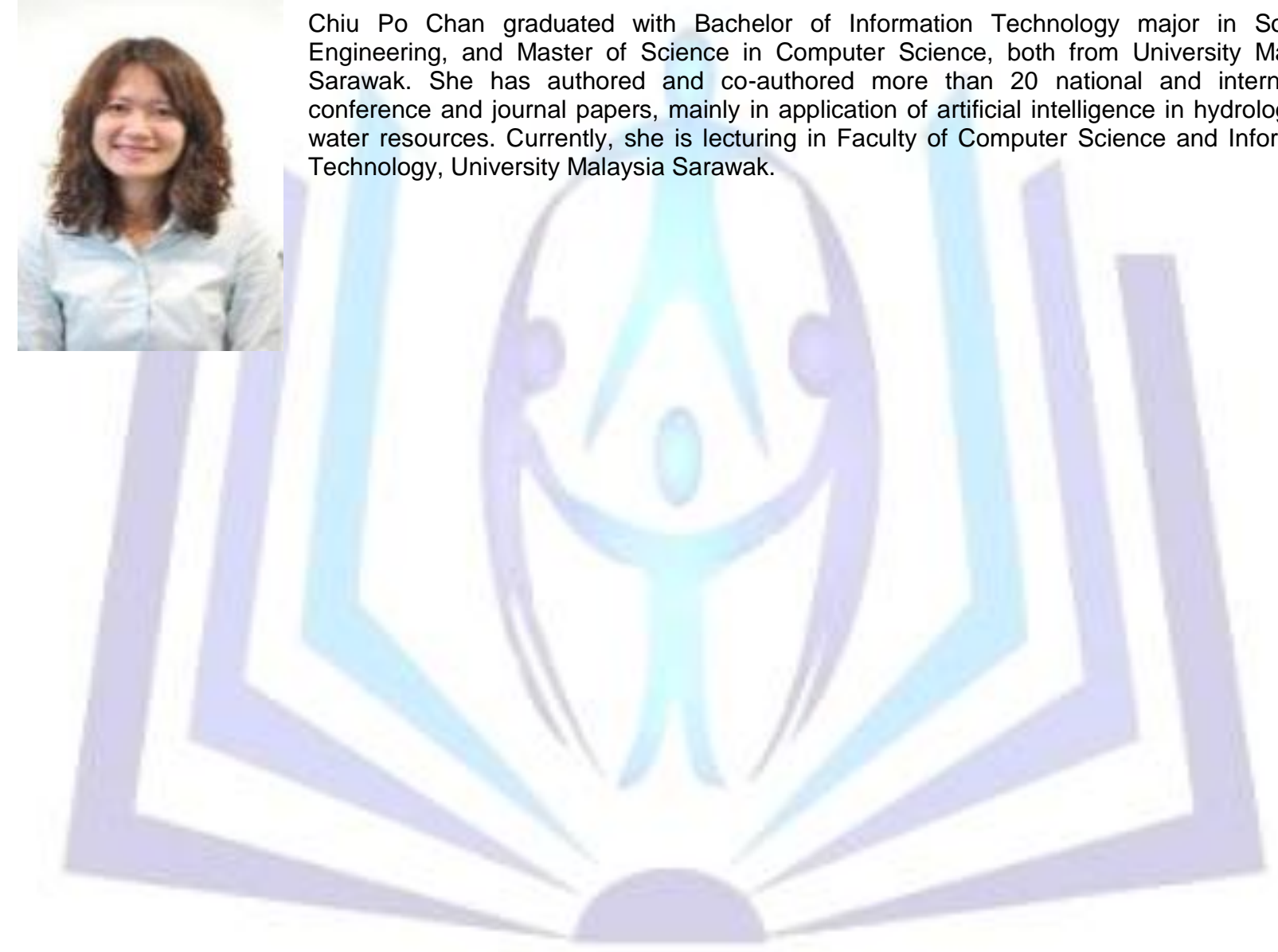

